\title{
Cognition, Quality Of Life And Mood State In Mild Traumatic Brain Injury: A Case Study
}

\author{
Prerna Sharma ${ }^{1}$, Susmita Halder ${ }^{2}$ \\ ${ }^{1}$ Assistant Professor, AIBHAS, Amity University, Uttar Pradesh. \\ ${ }^{2}$ Associate Professor, AIBHAS, Amity University, Kolkata.
}

Corresponding author: Susmita Halder

Email - shalder@kol.amity.edu

\begin{abstract}
Traumatic brain injury (TBI) is a one of occurrence with multiple possible neuropsychiatric symptoms, including problems with cognition, emotion, and behavior and deficits in social skills (Hartley 1995). Traumatic brain injury refers to a physiologically significant disruption of brain function resulting from the application of external physical force, including acceleration/deceleration forces (Marr et. al 2002). Severity level of traumatic brain injury can be classified as mild, moderate, and severe. In this context we wanted to study the cognitive functions, social deficits, and state of mood in an individual aftereffect of TBI frequent problems of cognitive, emotional, behavioral, physical, and psychosocial were reported in various studies and substantial source of at least temporary disability and stress to TBI survivors and their families. Hence, we have planned psychological and cognitive management for them. Therefore, in present study, a male of 26 years resident of Jaipur city was studied, the neuropsychological and behavioral functioning was assessed, and findings suggest that impairment in attention and concentration, visual motor functioning, and visuospatial functioning, anger, confusion-bewilderment and fatigue state and poor social relationship. Post psychological intervention improvement was observed.
\end{abstract}

Key words: Traumatic Brain Injury, Cognition, Mood state, Social relationship.

(Paper received $-10^{\text {th }}$ December 2020, Peer review completed $-20^{\text {th }}$ December 2020)

(Accepted $-22^{\text {nd }}$ December 2020)

\section{INTRODUCTION}

Traumatic brain injury (TBI) refers to a physiologically significant disruption of brain function resulting from the application of external physical force, including acceleration/ deceleration forces. There is several evidences of impaired brain functioning at the time of external physical force which include the episode of unconsciousness, memory loss of immediate events occurred before the trauma(retrograde amnesia) or memories after the trauma (anterograde amnesia), those are mainly known as posttraumatic amnesia; other than these, an alteration of mental state due to focal neurological deficit can also be seen [1]. Severity of TBI severity can be divided into mild, moderate, and severe levels of deficits, specifically based on the duration of loss of consciousness, posttraumatic amnesia, and/or Glasgow Coma Scale (GCS) score at the time of admission to the hospital. For more severe TBIs, neuropsychological deficits such as impairment of attention, memory and cognitive processing efficiency constitute a major category of potential adverse TBIrelated outcomes and can lead to significant functional impairment. For milder brain injuries, however, the evidence that these injuries lead to chronic neuropsychological deficits or functional impairment independently of psychiatric factors is less clear. Secondary and tertiary blast effects are common mechanisms of blast-related TBI, affecting the brain via contact and inertial forces-for example, the sudden 
acceleration/deceleration and rotation of an individual in a vehicle displaced by the force of the blast or by objects driven by the blast through the vehicle and against the individual's head. Biomechanical injury is accompanied by a cascade of injurious intra- and extracellular processes. Injury-induced calcium and magnesium dysregulation, excitatory amino acid excesses, calcium-regulated protein activation, mitochondrial dysfunction, free-radical formation, proteolysis are major elements of this postinjury cytotoxic cascade and contribute to traumatically induced neuronal injury and cell death. TBI also induces excessive neurotransmitter release, including functionally disruptive elevations in cerebral glutamate, acetylcholine, dopamine, norepinephrine, and serotonin levels [1].

A variety of cognitive and behavioural deficits can result from traumatic injury to the developing brain, including deficits in attention, memory, processing speed, and executive functions [2-6]. Executive function deficits have been tied to a lack of integrity of the frontal lobes of the brain. Magnetic resonance imaging studies of the pathophysiology of TBI suggest particular vulnerability of the frontal (i.e., dorsolateral cortex, orbitofrontal cortex, and frontal white matter) and anterior temporal lobes [7]. Some data have addressed the relation between frontal lobe damage and executive function subdomains. Children frequently exhibit neuropsychological difficulties associated with damage to the prefrontal regions with specific deficits in the executive functions such as planning, cognitive flexibility [8], behavioural inhibition, and poor organization of learning, memory, and language formulation [9]. Severity of TBI is related to specific deficits in executive functioning, such as planning, whereas injury to different regions of the frontal lobes results in different patterns of performance [7].

Cognitive training is required for the patients with TBI and the treatment focus should be upon the capacity and severity of symptoms in the patients as in case of schizophrenia also [10]. The impact of executive dysfunction may be amplified, rather than attenuated, with increasing time since injury [4]. It is estimated that nearly 1.5 to 2 million persons are injured and 1 million succumb to death every year in India. Road traffic injuries are leading cause (60\%) of TBIs followed by falls $(20-25 \%)$ and violence $(10 \%)$. Alcohol involvement is known to be present among $15-20 \%$ of TBIs at the time of injury [11].

\section{CASE SERIES}

Index patient is RJ, 26 years male resident of Jaipur, married for last 7 years has been part of the family business and belong to middle socio-economic status. When the incident happened, he was driving a motorcycle and met with an accident. He fall down from motorcycle, though there was no bleeding or serious physical injury but he got unconscious. He was immediately taken to General hospital trauma center and after some basic treatment shifted to in-patient ward and treatment continued for next 3 months. He was referred to Psychology clinic after 5 months of accident. In first visit his level of functioning was assessed and was found the patient was earlier going to the shop but currently due to injury he is at home. At the of pre assessment his right side of body not working at all as maximum injury was on the that part. He has some change in personality; he became very frank and more outspoken and easily get frustrated. During assessment, he was undergoing physiotherapy and his right side is impaired, his speech has become unclear, motivational, and living attitude tended to be diminished. It was found, he was able to stand with support and walk with support and able to maintain balance, his anger burst out are very common and often fights with his wife little matters. Detailed psychological assessment was done to find out the neuropsychological and behavioral deficits and further psychological intervention was planned for the client.

For assessment Rivermead Post-Concussion Symptoms Questionnaire (RPQ) [12], was administered to measure the severity of symptoms due to concussion and the presence and severity of post-concussion syndrome (PCS), a set of symptoms including cognitive, somatic, and emotional related to traumatic brain injury that may persist. PGI battery of brain dysfunction (PGI-BBD) [13], Trail making test (TMT) (parts A and B) [14], Controlled Oral word test (COWA) [15] administered to assess neuropsychological functioning and also WHO Quality of life (BREF) [16], Profile of Mood State also administered 
RESULTS

\begin{tabular}{|c|c|c|}
\hline \multicolumn{3}{|c|}{ The Rivermead Post -Concussion Questionnaire (RPQ) } \\
\hline & \multicolumn{2}{|c|}{ Score } \\
\hline RPQ-3 & \multicolumn{2}{|c|}{2} \\
\hline RPQ-13 & \multicolumn{2}{|c|}{25} \\
\hline \multicolumn{3}{|c|}{ PGI-BBD } \\
\hline Domains & Pre-intervention & \\
\hline Remote memory & Mild & $\begin{array}{c}\text { Post-intervention } \\
\text { Mild }\end{array}$ \\
\hline Recent memory & Mild & Mild \\
\hline Mental balance & Severe & Moderate \\
\hline Attention and concentration & Severe & Moderate \\
\hline Delayed recall & Mild & Mild \\
\hline Immediate recall & Mild & Mild \\
\hline Retention for similar pairs & $\begin{array}{c}\text { Mild } \\
\text { Severe }\end{array}$ & Mild \\
\hline Retention for dissimilar pairs & Severe & Moderate \\
\hline Visual retention & Severe & Moderate \\
\hline Recognition & Moderate & Moderate \\
\hline Nahor Benson test & Severe & Severe \\
\hline Bender gestalt test & Severe & Severe \\
\hline & d Oral Word Asso & (COWA) \\
\hline Pre-inter & & Post-intervention \} $\\
{\hline 3} &{ } &{4(4)} \\
{\hline} &{\text { rail Making Test (" }} &{ } \\
{\hline} &{\text { Pre-in }} &{\text { Post-inter }} \\
{\hline \text { TMT-A }} &{2 \text { minute }} &{\text { 2minutes }} \\
{\hline \text { TMT-B }} &{\text { 5minut }} &{4 \mathrm{mint}} \\
{\hline} &{\text { WHOQOL }} &{ } \\
{\hline \text { Physical health }} &{\text { Severe }} &{\text { No significant changes }} \\
{\hline \text { Psychological well being }} &{\text { Severe }} &{\text { No significant changes }} \\
{\hline \text { Social relationship }} &{\text { Severe }} &{\text { No significant changes }} \\
{\hline \text { Environment }} &{\text { Severe }} &{\text { No significant changes }} \\
{\hline} &{\text { file of Mood Stat }} &{ } \\
{\hline \text { Tension - anxiety }} &{\text { Moderate }} &{\text { Mild }} \\
{\hline \text { Depression }} &{\text { Mild }} &{\text { Mild }} \\
{\hline \text { Anger-hostility }} &{\text { Moderate }} &{\text { Moderate }} \\
{\hline \text { Viguour activity }} &{\text { Mild }} &{\text { Mild }} \\
{\hline \text { Fatigue }} &{\text { Moderate }} &{\text { Moderate }} \\
{\hline \text { Confusion bewilderment }} &{\text { Severe }} &{\text { Severe }} \\
$\hline
\end{tabular}

\section{DISCUSSION}

The aim of the present case study is to find out the neuropsychological and behavioral deficits in the mild traumatic brain injury patient. For index patient findings on assessment revealed some major impairments in different domains of cognition as well as behavioral functioning. On PGI battery of brain dysfunction results indicated severe impairment in mental balance and attention and concentration. Verbal and visual retention are also severely impairment and severe impairment in visual motor and visual spatial functioning can also be seen. Recognition is moderately impaired. On Trial Making Test Part A results indicate that severe impairment in attention and concentration on Part B results indicate that severe impairment in sustained attained. Moderate impairment was found in Executive function on Controlled Oral Word Association. Literature also suggested, damage of the rostral and ventral brain stem, thalamus results impairment in information processing in multiple cognitive domains, particularly attention, memory and executive function, damage in dorsolateral prefrontal cortex may result in impairment of executive functions [17]. These damages are commonly found in traumatic brain injury patients. It was also found that patients with brain damage has very poor memory functioning (including recent memory, mental balance, attention 
and concentration, delayed recall, visual retention and recognition were found to be impaired [18]. On the WHO quality of life scale, the major disturbance is found in psychological domain as he is not able to adjust with the current body image and functioning, moreover there are constant negative feelings associated. His social relationship and environment is moderately disturbed and the physical health domain as he is facing difficulty to following daily regime, energy is usually drained without doing any work and felt fatigue all day and facing pain and discomfort all over the body. In a study [19] it was found that personality changes, impulsivity and loss of memory decrease the quality of life for the brain injured person and their family. On Profile of mood states results reveal that severe impairment on the subscale of confusion -bewilderment, that means patient often feel confused in the environment and mostly unable to concentrate on the task provided, moderate impairment on the sub scale of tension -anxiety, anger-hostility and fatigue, this may be because of the injuries in the body the patient is unable to move from one place to another and fatigue throughout the day without doing any significant work. In the present study, it has been seen that, no significant changes can be seen on profile of mood states in post-intervention assessment other than the domain of tension, which indicates it might take more time and need long term psychological intervention to get some significant changes in mood state. In a study [20], there is empirical evidence to indicate that anxiety may exert a pronounced impact on the prognosis and course of recovery of an individual who has sustained a mild TBI. In a study [21], it was found that a positive and significant relationship between postinjury symptom frequency and tension/anxiety, anger/hostility, and perceived chronic stress existed. In adult individuals, with or without TBI might have cognitive decline and in accordance to severity of deficits cognition-focused intervention could be used as therapeutic measure [21].

\section{Psychological intervention including Cognitive retraining:}

After the detailed evaluation, psycho education of the family was started with focus on the current level of cognitive and psychological functioning and targets for psychotherapy. The activity schedule of the patient is also made to maintain a balance in daily routine and sleep hygiene was also advised to maintain. The family was also explained about the result of the evaluation, which areas need improvement and which areas will be focused in cognitive training. The family is also informed about the personality changes which are evident in the patient's behavior and how to deal with it.

For cognitive training total eight sessions were given; in the first session the focus is to improve his attention and concentration level and making him functionally independent. This included cognitive training modules with progressive difficulty (i.e., colour sorting and grain sorting) as well as making a significant daily activity schedule giving utmost importance to the patient convenience. Here, the patient first given 4 colours (red, green, blue and white) beads and ask to separate one colour beads (red colour) the time taken by patient was recorded by the therapist. Then in next trial the patient is asked to sort all colour beads separately, he was asked to repeat the same for next three trials, it was seen progressive improvement in speed of sorting. Similarly, the numbers of colours were increased to 5 , then to 6 . Grain sorting is started with three grains same instructions were given same as colour sorting. The patient's wife is advised to practice grain sorting and colour sorting for $30 \mathrm{~min}$ every day and record the time taken in every trial. In the next session also grain sorting and colour sorting was practiced. After 2 weeks slight changes in functional skills were evident but again there was a period of relapse as well as the aggression level had also increased. In the third session the patient was given letter cancelation and digit cancellation, the patient was instructed to cancel the alphabet in particular row. In the fourth session the patient was given pictures for colouring and mazes for further improving problem solving and sustaining concentration. He was also given simple addition sums and tasks to improve his flexibility. After 4 weeks, again neuropsychological evaluation was done where slight improvement was evident. However, the patient was advised to continue therapy sessions and practice at home.

Post assessment results suggest overall improvement in cognitive as well as daily living functioning. However, positive changes were more evident in cognitive skills like attention, mental balance, and retention rather than well- being and mood status. Results can be explained as cognitive training having early and direct impact on cognitive functions compared to improvement in psychological functioning which may require more intervention time. 


\section{CONCLUSION}

Several neurological and cognitive deficits have an adverse impact upon the patients with TBI and the prolonged psycho-therapeutic intervention is required to regenerate skills and functioning among them. Cognitive training has some immediate impact in changing the functionality but for the long-term process it would be helpful and advantageous to sustain the changes as well as to improve psychological well -being.

\section{REFERENCES}

1. Mckee AC, Daneshvar DH. The neuropathology of traumatic brain injury. Handb Clin Neurol 2015;127,4566.

2. Anderson V, Catroppa C, Morse S, Haritou F, Rosenfeld J. Recovery of intellectual ability following traumatic brain injury in childhood: impact of injury severity and age at injury. Pediatr Neurosurg 2000;32(6):282-90.

3. Light R, Asarnow R, Satz P, Zaucha K, McCleary C, Lewis R. Mild closed-head injury in children and adolescents: Behavior problems and academic outcomes. J Consult Clin Psychol 2010;66(6): 1023-9.

4. Dennis M, Barnes MA, Donnelly RE, Wilkinson M, Humphreys RP. Appraising and managing knowledge: Metacognitive skills after childhood head injury. Dev Neuropsychol 2003;12(1):77-103.

5. Ewing-Cobbs L, Kramer L, Prasad M, Canales DN, Louis PT, Fletcher JM, Vollero H, Landry SH, Cheung $\mathrm{K}$. Neuroimaging, physical, and developmental findings after inflicted and noninflicted traumatic brain injury in young children. Pediatrics 1998;102(2):300-7.

6. Fletcher JM, Ewing-Cobbs L, Miner ME, Levin HS, Eisenberg HM. Behavioral changes after closed head injury in children. J Consult Clin Psychol 1990;58(1):93-100.

7. Levin HS, Mendelsohn D, Lilly MA, Fletcher JM, Culhane KA, Chapman SB, Harward H, Kusnerik L, Bruce $\mathrm{D}$, Eisenberg HM. Tower of London performance in relation to Magnetic Resonance Imaging following closed head injury in children. Neuropsychology 1994;8(2):171-90.

8. Ylvisaker M, Szekeres SF, Hartwick P. Cognitive rehabilitation following traumatic brain injury in children. In Advances in child neuropsychology 1992 (pp. 168-214). Springer, New York, NY.

9. Levin HS, Song J, Scheibel RS, Fletcher JM, Harward H, Lilly M, Goldstein F. Concept formation and problem-solving following closed head injury in children. J Int Neuropsychol Soc 1997;3(6):598-607.

10. Halder S, Mahato A. Cognitive Impairment in Schizophrenia: An Overview of Assessment and Management. Int J Indian Psychol 2012;2:64-72.

11. Gururaj G. Epidemiology of traumatic brain injuries: Indian scenario. Neurol Res 2002;24(1):24-8.

12. King NS, Crawford S, Wenden FJ, Moss NEG, Wade DT. The Rivermead Post-Concussion SymptomsQuestionnaire: a measure of symptoms commonly experienced after head injury and its reliability $\mathrm{J}$ Neurol 1995;242:587-92.

13. Pershad D, Verma SK. Handbook of PGI Battery of Brain Dysfunction (PGI-BBD). National Psychological Corporation ; 1990.

14. Corrigan JD, Hinkeldey MS. Relationships between parts A and B of the Trail Making Test. J. Clin Psychol 1987;43(4):402-9.

15. Ross TP. The reliability of cluster and switch scores for the Controlled Oral Word Association Test. Arch Clin Neuropsychol 2003;18:153-64.

16. Boyle GJ, Helmes E, Matthews G, Izard CE. Chapter 8 - Measures of Affect Dimensions, Measures of Personality and Social Psychological Constructs,Academic Press, 2015, Pp 190-224.

17. Silver MA, Kastner S. Topographic maps in human frontal and parietal cortex. Trends Cogn Sci 2009;13(11):488-95.

18. Sinha S, Gunawat P, Nehra A, Sharma BS. Cognitive, functional, and psychosocial outcome after severe traumatic brain injury: A cross-sectional study at a tertiary care trauma center. Neurol India 2013;61(5):501-6.

19. Obonsawin MC, Jefferis S, Lowe R, Crawford JR, Fernandes J, Holland L, Woldt K, Worthington E, Bowie G. A model of personality change after traumatic brain injury and the development of the Brain Injury Personality Scales. J Neurol Neurosurg Psychiatry 2007;78(11):1239-47.

20. Moore E, Indig D, Haysom L. Traumatic brain injury, mental health, substance use, and offending among incarcerated young people. J Head Traum Rehabil 2010;29(3):239-47.

21. Bay E, Donders J. Risk factors for depressive symptoms after mild-to-moderate traumatic brain injury. Brain Injury 2008;22(3):233-41.

22. Halder S, Mahato AK. Neurocognitive psychotherapy for adult attention deficit hyperactive disorder. Industr Psychiatry J 2009;18:113-6

$* * * * * * * * * * * * * * * * * * * * * * * * * * * * * * * * * * *$

Acknowledgements - Nil; Conflict of Interest - Nil; Funding - Nil.

Indian Journal of Mental Health 2021;8(1) 